\title{
Long-Term Tea Consumption and Depressive and Anxiety Symptoms in Elderly
}

To the editor, the publication on "Associations of LongTerm Tea Consumption with Depressive and Anxiety Symptoms in Community-Living Elderly" is very interesting (1). Chan et al. concluded that "There was evidence suggesting that long-term tea consumption was associated with reduced depressive and anxiety symptoms among community-living elderly (1)." In fact, tea drinking is a rooted behavior among Chinese Asian population. The health usefulness of tea is approved. Neuroprotective system due to tea drinking is believed to due to the active ingredients including to flavonoids (2). In a recent report, the green tea was found to have more neuroprotective activity than red and black tea (3). It is no doubt that the long-term tea consumption can result in neuroprotective effect as reported by Chan et al (1). However, as noted by Chan, further investigation is needed. The main concern for the present report is confounding effect that is not controllable. The studied elderly might have other foods, beverages or activities that can help protect against depressive and anxiety symptoms. Finally, tea contain caffeine, an extremely high dose drinking might result in problem, induction of anxiety instead of prevention of anxiety (4).

Conflict of interest: None
B. Joob ${ }^{1}$, V. Wiwanitkit ${ }^{2}$

1. Sanitation1 Medical Academic Center, Bangkok Thailand; 2. Visiting professor, Hainan Medical University, China

Corresponding Author: Beuy Joob, Sanitation1 Medical Academic Center, Bangkok Thailand, Email: beuyjoob@hotmail.com

Received November 23, 2017

Accepted for publication November 30, 2017

J Prev Alz Dis 2018;5(1):87

Published online January 10, 2018, http:/ / dx.doi.org/10.14283/jpad.2018.3

\section{References}

1. Chan SP, Yong PZ, Sun Y, Mahendran R, Wong JCM, Qiu C, Ng TP, Kua $\mathrm{EH}$, Feng L. Associations of Long-Term Tea Consumption with Depressive and Anxiety Symptoms in Community-Living Elderly: Findings from the Diet and Healthy Aging Study. J Prev Alz Dis 2018;5(1):21-25

2. Panche AN, Diwan AD, Chandra SR. Flavonoids: an overview. J Nutr Sci. 2016 Dec 29;5:e47.

3. Schimidt HL, Garcia A, Martins A, Mello-Carpes PB, Carpes FP. Green tea supplementation produces better neuroprotective effects than red and black tea in Alzheimer-like rat model. Food Res Int. 2017 Oct;100(Pt 1):442-448.

4. Mino Y, Yasuda N, Fujimura T, Ohara H. Caffeine consumption and anxiety and depressive symptomatology among medical students. Arukoru Kenkyuto Yakubutsu Ison. 1990 Dec;25(6):486-96.
Responses: We thank Dr Joob and Dr Wiwanitkit for their interest in our research work and the valuable comments and suggestions they have provided. I fully agree with them that some uncontrolled factors, such as the intake of other foods, beverages or activities, may help protect against depressive and anxiety symptoms, and hence residual confounding cannot be completely ruled out. Further investigation is needed for a definitive conclusion. Indeed, motivated by growing evidence on neuroprotective benefits of tea consumption (1), my coworkers and I are now planning a new study in which we aim to assess the effects of tea drinking on brain health in a randomized controlled trial.

Based on research study conducted among medical students, Drs Joob and Wiwanitkit also pointed out that an extremely high level of tea drinking might result in anxiety, because of caffeine. Our study focused on elderly population and normal levels of tea drinking observed in people's daily life. In our studies, we did not calculate caffeine intake but there are studies that support caffeine as a neuroprotective factor (2). While controversy exist on the optimal dosage, in view of potential adverse effects of high caffeine intake, I think the best recommendation at this moment is to consume tea in moderation. To obtain cognitive and psychological benefits, I think one to two cup a day is good enough.

\section{Feng}

Corresponding author: Department of Psychological Medicine, Yong Loo Lin School of Medicine, National University of Singapore, Email: pcmfl@nus.edu.sg

Received December 8, 2017

Accepted for publication December 12, 2017

J Prev Alz Dis 2018;5(1):87

Published online January 10, 2018, http:/ / dx.doi.org/10.14283/jpad.2018.4

\section{References}

1. Feng L, Chong MS, Lim WS, Lee TS, Kua EH, Ng TP. Tea for Alzheimer Prevention. J Prev Alz Dis 2018;5(1):21-25

2. Carman AJ, Dacks PA, Lane RF, Shineman DW, Fillit HM. Current evidence for the use of coffee and caffeine to prevent age-related cognitive decline and Alzheimer's disease. The journal of nutrition, health \& aging 2014; 18(4): 38392. 